\title{
Caracterização Anatômica e Física do Bambu Gigante (Dendrocalamus giganteus Munro)
}

\author{
Flávia Maria Silva Brito ${ }^{1}$, Juarez Benigno Paes ${ }^{1}$, José Tarcísio da Silva Oliveira ${ }^{1}$, \\ Marina Donária Chaves Arantes ${ }^{1}$, Humberto Fantuzzi Neto ${ }^{1}$ \\ ${ }^{1}$ Departamento de Ciências Florestais e da Madeira, Universidade Federal do Espirito Santo - UFES, \\ Jeronimo Monteiro/ES, Brasil
}

\begin{abstract}
RESUMO
O trabalho objetivou realizar a caracterização anatômica e física de hastes adultas do bambu Dendrocalamus giganteus Munro. Assim, foram coletadas quatro hastes e seccionadas em colmos de 2,10 m de comprimento. Das extremidades dos colmos foram obtidos discos de 5,0 cm de espessura, os quais foram transformados em corpos de prova para a caracterização anatômica e física. Foram mensurados o percentual de fibras, de vasos e de parênquima, o teor de umidade, as massas específicas básica e anidra e a retratibilidade. O bambu estudado possui frequência de vasos de 0 a 4 vasos $\mathrm{mm}^{-2}$, média de 2 vasos $\mathrm{mm}^{-2}$, fibras com comprimento médio de $2,72 \mathrm{~mm}$ e o parênquima compõe $50,72 \%$ do colmo. O teor de umidade foi quantificado em $60 \%$; a massa específica básica, em $0,66 \mathrm{~g} \mathrm{~cm}^{-3 ;}$ a anidra, em $0,83 \mathrm{~g} \mathrm{~cm}^{-3}$; a retratibilidade volumétrica, em $15,40 \%$. Observou-se que as características físicas do bambu foram influenciadas pela disposição e pela proporção dos elementos anatômicos.
\end{abstract}

Palavras-chave: feixes fibrovasculares, tecido parenquimático, massa específica, retratibilidade.

\section{Giant Bamboo (Dendrocalamus giganteus Munro) Anatomical and Physical Characterization}

\begin{abstract}
The work aimed to carry out the anatomical and physical characterizations of adult bamboo rods of Dendrocalamus giganteus Munro. So, four rods were collected and sectioned in culms of $2.10 \mathrm{~m}$ long. From the ends of the culms were obtained $5.0 \mathrm{~cm}$ thick disks that were transformed into samples for anatomical and physical characterizations. In this study, were measured the percentage of fibers, vessels, parenchyma, the moisture content, the basic specific gravity and oven dry specific gravity and shrinkage. The studied bamboo has 0 to 4 vessels $\mathrm{mm}^{-2}$, with average of 2 vessels $\mathrm{mm}^{-2}$, with average fiber length of $2.72 \mathrm{~mm}$ and $50.72 \%$ consists of parenchyma tissue. The moisture content was quantified at $60 \%$, the basic specific gravity in $0.66 \mathrm{~g} \mathrm{~cm}^{-3}$, the oven dry specific gravity in $0.83 \mathrm{~g} \mathrm{~cm}^{-3}$ and volumetric shrinkage in $15.40 \%$. It was observed that the bamboo physical characteristics were influenced by the layout and anatomical elements proportion.
\end{abstract}

Keywords: fibrovascular bundles, parenchyma tissue, specific gravity, shrinkage. 


\section{INTRODUÇÃO}

O bambu é utilizado desde os tempos mais remotos e pode ser aproveitado como alimento humano, forragem animal, biomassa energética, material de construção, matéria-prima industrial em diversos setores, artesanato e movelarias. Dessa forma, gera emprego e influencia na renda dos países que processam e utilizam o bambu.

O Dendrocalamus giganteus Munro é uma espécie de rápido crescimento e versátil (Almeida et al., 2000). Aspectos como espessura da parede, diâmetro e linearidade longitudinal do colmo, comprimento das hastes, aliada à produtividade florestal, fazem dela uma espécie apropriada para reflorestamentos e utilizações industriais (Ostapiv, 2011), inclusive para confecção de laminado colado (Beraldo \& Rivero, 2003).

De acordo com Pereira \& Beraldo (2008), o Dendrocalamus giganteus, conhecido como bambu-gigante ou bambu-balde, possui grande porte e pertence ao grupo dos entouceirantes. A altura dos colmos varia entre 24 a $40 \mathrm{~cm}$, e o diâmetro, de 10 a $20 \mathrm{~cm}$. Possui um bom desenvolvimento em regiões tropicais úmidas e regiões subtropicais, em solos férteis e suporta temperaturas mínimas até $-2^{\circ} \mathrm{C}$.

Segundo Salamon (2009), o bambu não possui o mesmo diâmetro nem a mesma espessura de parede do colmo ao longo das hastes em função disso, suas qualidades físicas são variáveis de um extremo a outro e pode resultar em problemas para a construção civil. Segundo Beraldo \& Azzini (2004), os nós e os entrenós influenciam as propriedades do colmo do bambu. Grande parte dessas estruturas são constituídas por feixes fibrovasculares que se encontram envolvidos em um tecido parenquimatoso rico em substâncias de reserva, na forma de amido. A distribuição geral dos elementos anatômicos presentes nos colmos do bambu é: $50 \%$ de parênquima, $40 \%$ de fibra e $10 \%$ de tecidos condutores (Pereira \& Beraldo, 2008).

De acordo com Pereira \& Beraldo (2008), as fibras constituem o tecido esclerenquimático, estão bem concentradas nos internós e protegem os feixes vasculares, formando de 40 a $50 \%$ do tecido total do colmo e 60 a $70 \%$ de sua massa. O comprimento das fibras varia em função da posição no colmo, aumentando, geralmente, da periferia para o centro e reduzindo até a parte interna. Enquanto as fibras mais curtas são encontradas próximas dos nós, as mais longas concentram-se no meio dos internós.
$\mathrm{Na}$ direção vertical, elas aumentam em quantidade no sentido longitudinal da haste de bambu, e o tecido parenquimático é reduzido.

Conforme Beraldo \& Azzini (2004), o parênquima é constituído de células alongadas, distribuídas no sentido axial e intercaladas por células prismáticas menores. Esse tecido encontra-se bem concentrado nas camadas da parede interna dos colmos e diminuem gradativamente nas camadas mais externas. Na direção longitudinal, ele é reduzido no sentido base-topo dos colmos do bambu. Os vasos são alargados e pouco numerosos nas camadas mais internas dos colmos, enquanto na camada externa são menores e mais numerosos.

Segundo Beraldo \& Rivero (2003), o bambu possui boas características físicas. As dimensões de seus colmos podem ser alteradas em função da absorção e da liberação de água, que afastam as células (Ferreira, 2007). Conforme Hidalgo Lopez (2003), a umidade é constante em hastes jovens, mas, em maduras, ela decresce no sentido longitudinal. Para Ferreira (2002), é inversamente proporcional ao desenvolvimento do colmo, sendo influenciado pela idade e pela estação do ano. No processo de secagem, o bambu pode retrair.

O inchamento e a contração que ocorre no processo de secagem são influenciados pela presença ou ausência de nós no material processado. Após o processo de usinagem, a região dos nós pode ter inchamento ou retração menor que a região dos internós. Por isso, depois do processo de secagem, o bambu varia com maior amplitude na região em que não existem nós e com menor amplitude na região dos nós. Esse fenômeno pode desencadear uma tensão interna, promovida pela umidade ou pela temperatura, provocando a formação de fissuras no material (Ostapiv, 2011).

Assim, para o emprego do bambu como matéria-prima economicamente viável, este trabalho objetivou realizar a caracterização anatômica e física de hastes adultas do bambu Dendrocalamus giganteus.

\section{MATERIAL E MÉTODOS}

\subsection{Procedência e coleta do bambu}

Os colmos utilizados foram coletados nas proximidades de Alegre, região Sul do estado do Espírito Santo. O município está localizado nas coordenadas 
de $20^{\circ} 44^{\prime} 49^{\prime \prime}$ de latitude $S, 41^{\circ} 27^{\prime} 58^{\prime \prime}$ de longitude W e altitude de $127 \mathrm{~m}$. Na classificação internacional de Köppen, o clima da região é caracterizado como tropical quente e úmido, com inverno frio e seco, temperatura anual média de $23,1^{\circ} \mathrm{C}$ e precipitação total anual média de $1.341 \mathrm{~mm}$ (Lima et al., 2008).

Foram utilizados bambus da espécie Dendrocalamus giganteus Munro em idade adulta, escolhidos em função das suas boas características físico-mecânicas, como comprimento das hastes, diâmetro e espessura da parede do colmo. Os bambus foram coletados em uma touceira e selecionados pelos sinais de manchas e ramificações, que são parâmetros fundamentais para considerar a idade adulta do bambu. Para o abate das hastes, utilizaram-se motosserra e ferramentas manuais (facão e machado). Foram coletadas quatro hastes de bambu, com idade superior a três anos, para confecção das taliscas e dos corpos de prova.

Os bambus coletados possuíam altura das hastes em torno de $25 \mathrm{~m}$, circunferência do colmo variando de $13 \mathrm{a} 15 \mathrm{~cm}$, comprimento dos internós entre 30 e $40 \mathrm{~cm}$ e espessura da parede do colmo de 0,7 a $2,5 \mathrm{~cm}$. A circunferência média geral dos colmos coletados foi de 14,0 cm. Após a extração, os bambus foram seccionados ao longo das hastes a cada $2,1 \mathrm{~m}$, das quais se retirou na base de cada seção um disco de 5,0 cm, perfazendo no total 26 discos de bambu. Estes foram utilizados para confecção dos corpos de prova com dimensões de $1,0 \times 2,0 \times 2,0 \mathrm{~cm}$ (espessura $\times$ comprimento $\times$ largura) e direcionados às análises físicas e anatômicas (Figura 1).

\subsection{Caracterização anatômica dos colmos do bambu}

Para a caracterização anatômica, os corpos de prova foram retirados apenas da base das hastes do bambu, por conter uma maior representatividade dos elementos anatômicos. As amostras da parede do colmo foram seccionadas com 1,0 ×2,0 $\times 2,0 \mathrm{~cm}$ (espessura $\times$ largura $\times$ comprimento). Seguiram-se as recomendações da IAWA Committiee (IAWA, 2007) e Comisión Panamericana de Normas Técnicas (COPANT) (1974), uma vez que não existem tais procedimentos para bambu.

Para mensurar os elementos vasculares e parênquima, as amostras foram fervidas em água e, posteriormente, fixadas em micrótomo de deslize para obtenção dos

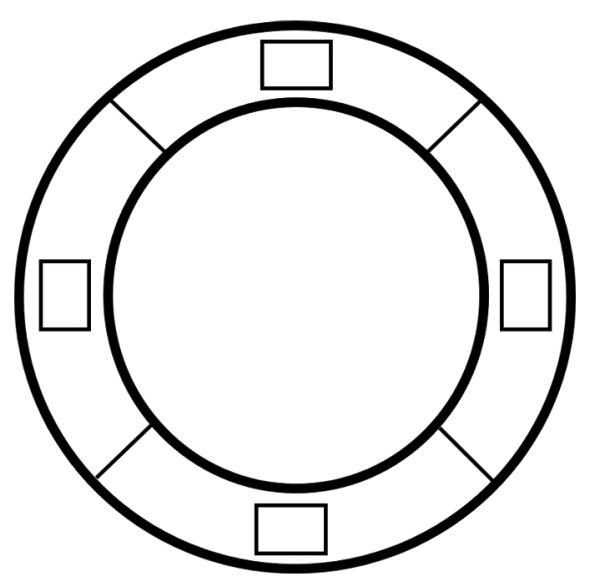

Figura 1. Posições no disco em que as amostras para caracterização anatômica e física do bambu foram obtidas.

Figure 1. Positions in the disc where the samples for anatomical and physical characterizations of bamboo were obtained.

cortes histológicos e realizadas as fotomicrografias para mensurar a frequência vascular $\left(\mathrm{n} \mathrm{mm}^{-2}\right)$, o diâmetro dos poros $(\mu \mathrm{m})$ e o parênquima (\%).

Para obtenção das fotomicrografias de vasos e fibras, foi utilizada uma câmera acoplada a um microscópio óptico de ocular micrométrica, sendo o software para a análise de imagem o Image Pro Express 6.0. Para quantificar o parênquima, foi utilizado o Paint.NET, versão 3.5.10, com o valor dado em porcentagem.

Para os vasos, foram utilizadas 15 lâminas histológicas e, de cada uma delas, foram realizadas 20 medições do diâmetro e da frequência dos vasos, totalizando 300 medições. As fotomicrografias foram divididas em duas áreas $\left(\mathrm{mm}^{2}\right)$ para quantificar o número e o diâmetro dos vasos. A obtenção do valor médio do diâmetro deu-se pela retirada das medidas ortogonais de todos os vasos.

Para dissociação dos elementos anatômicos e para mensuração das fibras, as amostras foram transformadas em palitos e tratadas com solução macerante, de acordo com o método de Nicholls, descrito por Ramalho (1987). O material submetido à maceração foi transferido para um frasco de $25 \mathrm{~mL}$ contendo solução de ácido acético e peróxido de hidrogênio na proporção de 1:1. Os frascos foram lacrados e transferidos para estufa a 
temperatura de $60 \pm 2^{\circ} \mathrm{C}$, até ocorrer a individualização dos elementos anatômicos. O material foi lavado com água destilada e corado com safranina. Foram preparadas lâminas histológicas com a utilização de água destilada e glicerina na proporção de 1:1 e, posteriormente, foram obtidas as fotomicrografias.

Para quantificar as fibras, foram confeccionadas 12 lâminas histológicas e realizadas 20 medições do comprimento, largura e diâmetro do lume, totalizando 240 medições, e, em seguida, com base na largura e diâmetro do lume, foi calculada a espessura da parede celular.

\subsection{Caracterização física dos colmos do bambu e avaliação estatística}

Para a realização da caracterização física, foram empregados corpos de prova com dimensões de $1,0 \times 2,0 \times 2,0 \mathrm{~cm}$ (espessura $\times$ largura $\times$ comprimento). As amostras foram obtidas apenas da região intermediária, desprezando as camadas externa e interna dos colmos para quantificação da umidade, da densidade e da retratibilidade.

As propriedades físicas foram determinadas de acordo com a Norma Brasileira Regulamentadora - NBR 7190 da Associação Brasileira de Normas Técnicas - ABNT (1997). Para cada característica analisada, avaliaram-se o valor médio, mínimo, máximo e o desvio-padrão.

\section{RESULTADOS E DISCUSSÃO}

\subsection{Anatomia dos colmos do bambu}

Foram observados elementos vasculares, envolvidos por feixes de fibras que possuem valores extremos de diâmetros pequenos $(63,00 \mu \mathrm{m})$ e grandes $(245,67 \mu \mathrm{m})$, com predominância de vasos médios $(149,81 \mu \mathrm{m})$.

A frequência dos elementos vasculares variou de $0 \mathrm{a}$ 4 vasos $\mathrm{mm}^{-2}$ e a média ficou em torno de 2 vasos $\mathrm{mm}^{-2}$, evidenciando a quantidade escassa desses elementos anatômicos na espécie Dendrocalamus giganteus. A porcentagem de vasos analisada na seção transversal do colmo esteve em torno de 10\% (Figura 2). A mesma porcentagem de vasos é citada por George (1985); Pereira \& Beraldo (2008). No entanto, Beraldo \& Zoulalian (1995), ao trabalharem com a mesma espécie, encontraram uma porcentagem de $11 \%$ de vasos na camada interna do colmo.

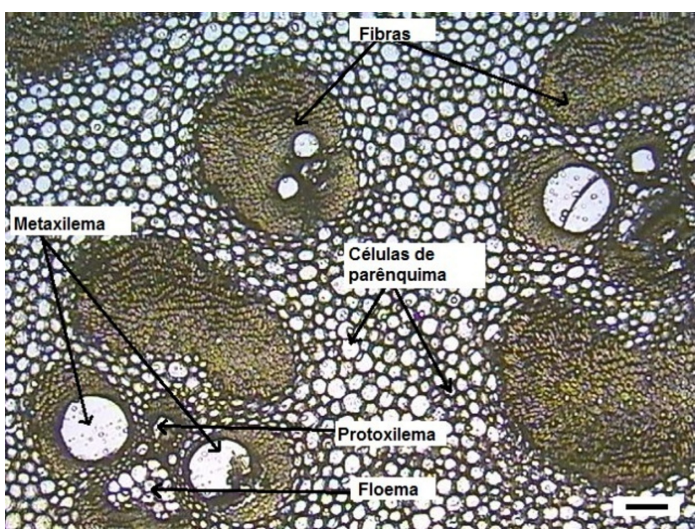

Figura 2. Estrutura anatômica do bambu Dendrocalamus giganteus. Escala $=100 \mu \mathrm{m}$.

Figure 2. Anatomical structure of Dendrocalamus giganteus bamboo. Scale $=100 \mu \mathrm{m}$.

Os vasos de bambu, visíveis sob lente de dez aumentos, encontraram-se agrupados em cachos, sendo mais numerosos próximos à região externa do colmo do bambu e com menores diâmetros. Na região interna estão em pequenas quantidades, porém possuem diâmetros maiores, por isso a parte interna da parede dos colmos normalmente possui baixa massa específica. O diâmetro e a quantidade dos vasos influenciam na difusão de substâncias preservativas, pois a quantidade de preservativo que circula pelos vasos do colmo é pequena (George, 1985; Tiburtino, 2012).

Em relação à porcentagem de parênquima, observou-se que esse tecido ocupa uma área de 50,72\% da composição do colmo para a espécie analisada (Figura 2). É constituído de células alongadas no sentido longitudinal e intercaladas por células prismáticas curtas. Esse tecido foi mais abundante nas camadas internas do colmo, diminuindo no sentido da camada mais externa, e tem por objetivo armazenar água e amido, razão pela qual o bambu é facilmente atacado por bactérias, fungos e insetos, principalmente pelo Dinoderus minutus Fab. O tecido parenquimático envolve os feixes fibrovasculares do bambu (Figura 2).

O Dendrocalamus giganteus possui células de parênquima e fibras longas e estreitas (Figura 3). Estas possuem comprimento médio de 2,72 $\pm 0,95 \mathrm{~mm}$ (média \pm desvio padrão), mas variando de 1,13 a 5,41 mm. O valor do comprimento médio está de acordo com o encontrado por Miskalo (2009) para a espécie, que foi de 3,2 mm. Azzini \& Beraldo (2000) observaram na base e no meio dos colmos um comprimento de $2,86 \mathrm{~mm}$ 


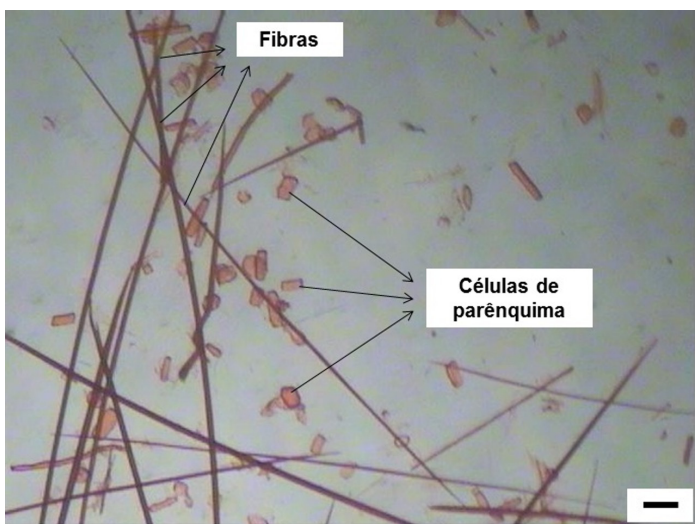

Figura 3. Fibras e células de parênquima do bambu Dendrocalamus giganteus. Escala $=100 \mu \mathrm{m}$.

Figure 3. Fibers and parenchyma cells of Dendrocalamus giganteus bamboo. Scale $=100 \mu \mathrm{m}$.

para esse mesmo elemento anatômico. Esses valores foram semelhantes aos obtidos neste estudo. Segundo Miskalo (2009), a variação entre os comprimentos de fibras ocorre na parede do colmo, sendo mais curta na parte externa e mais longa no centro.

Para a COPANT (1974), o comprimento médio encontrado para as fibras pode ser classificado como intermediário, pois ocupa uma posição entre fibras de Pinus (3,5 mm) e de eucalipto (1,0 mm). O comprimento de fibra explica a grande resistência mecânica que oferece a alguns produtos, como piso de bambu laminado colado, caixas e papel para embalagens. Em relação à largura das fibras, o valor médio foi de $23,87 \mu \mathrm{m}$, com o mínimo de $10,45 \mu \mathrm{m}$ e o máximo de $34,89 \mu \mathrm{m}$. O diâmetro médio do lume foi de $3,50 \mu \mathrm{m}$, com valor máximo de $8,76 \mu \mathrm{m}$ e mínimo de $0,17 \mu \mathrm{m}$. A espessura média da parede foi de $10,09 \mu \mathrm{m}$, sendo a mínima de $5,14 \mu \mathrm{m}$ e a máxima de $15,12 \mu \mathrm{m}$.

\subsection{Características físicas do bambu}

A média geral da umidade das amostras provenientes do campo foi de $60 \pm 27 \%$. A posição de retirada das amostras influenciou os resultados da umidade das amostras. Observou-se que esse parâmetro foi decrescente no sentido base-topo das hastes. Segundo Liese (1998), esse parâmetro tem tendência à redução no sentido base-topo e, de acordo com Hidalgo Lopez (2003); Berndsen et al. (2009), pode ser influenciado pela idade, época de corte, condições edafoclimáticas e precipitação pluviométrica, evidenciando, assim, variações conforme o local da colheita.

Berndsen et al. (2009) realizaram um estudo com o bambu-mossô (Phyllostachys pubescens Mazel ex $\mathrm{H}$. de Lehaie), cujas amostras foram retiradas de diferentes idades e posições no colmo, e observaram que os valores encontrados para massa específica básica média tiveram acréscimo em relação à sua localização no colmo. Esse fato poderia explicar a redução da umidade no sentido longitudinal com a redução dos lumes e o aumento da espessura das paredes dos feixes fibrovasculares.

Foi encontrado para massa específica básica um valor médio de $0,66 \pm 0,14 \mathrm{~g} \mathrm{~cm}^{-3}$, sendo observado um acréscimo no sentido base-topo. Isso se explica pela grande concentração dos feixes fibrovasculares no topo das hastes e pela redução das células parenquimáticas nessa região.

Segundo Liese (1998), a massa específica básica é uma propriedade importante dos colmos de bambu e pode variar de 0,50 a $0,90 \mathrm{~g} \mathrm{~cm}^{-3}$, inclusive dentro de uma mesma espécie. Para madeira, esse valor é classificado como intermediário e pode indicar boas propriedades mecânicas. Brito et al. (1987) realizaram um trabalho com a espécie Bambusa vulgaris Schrad. ex J. C. Wendl. e observaram o mesmo modelo de variação da massa específica (crescente da base para o topo). Para o Dendrocalamus giganteus, esses autores obtiveram valores médios de $0,74 \mathrm{~g} \mathrm{~cm}^{-3}$. Ciaramello \& Azzini (1971) pesquisaram quatro espécies diferentes do gênero Dendrocalamus e encontraram valores variáveis: $0,60 \mathrm{~g} \mathrm{~cm}^{-3}$ para Dendrocalamus asper F. Niger (Hitam), $0,68 \mathrm{~g} \mathrm{~cm}^{-3}$ para Dendrocalamus latiflorus Munro, $0,67 \mathrm{~g} \mathrm{~cm}^{-3}$ para Dendrocalamus strictus (Roxb.) Nees e $0,55 \mathrm{~g} \mathrm{~cm}^{-3}$ para Dendrocalamus giganteus.

Para a massa específica anidra, foi obtido um valor de $0,83 \pm 0,08 \mathrm{~g} \mathrm{~cm}^{-3}$. Observou-se a mesma tendência de variação da massa específica básica, ou seja, crescente no sentido longitudinal. Os valores encontrados estão relacionados à influência da densidade sobre outras propriedades do bambu, que pode conferir uma maior resistência ao material.

A estabilidade dimensional do bambu foi determinada por meio das propriedades de retração e de inchamento, com o objetivo de determinar a utilização industrial do bambu in natura e as relações existentes entre retratibilidade e expansão volumétrica, 
Tabela 1. Valores médios dos parâmetros de inchamento e de contração do bambu (Dendrocalamus giganteus) em função do tempo de saturação e de secagem das amostras.

Table 1. Average values of parameters of swelling and shrinkage of bamboo (Dendrocalamus giganteus) to saturation and drying times of samples.

\begin{tabular}{|c|c|c|c|c|}
\hline \multirow{3}{*}{ Direção } & \multicolumn{4}{|c|}{ Inchamento (\%) } \\
\hline & \multicolumn{4}{|c|}{ Tempo (horas) } \\
\hline & 24 & 48 & 72 & 96 \\
\hline Espessura (Radial - R) & $6,00 \pm 3,70^{*}$ & $7,90 \pm 4,20$ & $11,40 \pm 5,50$ & $16,40 \pm 9,80$ \\
\hline Largura (Tangencial - T) & $4,10 \pm 1,90$ & $5,20 \pm 1,70$ & $5,90 \pm 4,00$ & $10,90 \pm 6,10$ \\
\hline Relação T/R & $0,68 \pm 0,98$ & $0,68 \pm 0,50$ & $0,52 \pm 0,34$ & $0,67 \pm 1,67$ \\
\hline \multirow{3}{*}{ Direção } & \multicolumn{4}{|c|}{ Contração (\%) } \\
\hline & \multicolumn{4}{|c|}{ Tempo (horas) } \\
\hline & 24 & 48 & 72 & 96 \\
\hline Espessura (Radial - R) & $5,80 \pm 3,20$ & $7,30 \pm 3,50$ & $10,60 \pm 4,30$ & $14,00 \pm 7,00$ \\
\hline Largura (Tangencial - T) & $4,10 \pm 1,70$ & $5,30 \pm 1,60$ & $5,60 \pm 3,60$ & $10,00 \pm 5,00$ \\
\hline Relação T/R & $0,72 \pm 0,95$ & $0,72 \pm 0,46$ & $0,53 \pm 0,34$ & $1,01 \pm 0,25$ \\
\hline
\end{tabular}

*Valor médio \pm desvio padrão.

que são essenciais para um aproveitamento mais eficiente do material. Na Tabela 1, estão os valores médios encontrados para o inchamento e a contração do bambu Dendrocalamus giganteus.

Observou-se que o bambu possui variação mínima no eixo longitudinal, por isso os valores não foram expostos neste trabalho. Em relação à espessura (radial) e à largura (tangencial), foi observado que ocorrem variações nos valores, principalmente no sentido da largura (tangencial) do bambu. Segundo Pereira \& Beraldo (2008), os valores médios das variações nas duas direções (radial e tangencial) geralmente são menores que os valores encontrados para madeira da ordem de $6 \%$ na direção radial e $10 \%$ na direção tangencial. Neste estudo, a média encontrada foi maior na direção radial e menor na direção tangencial do que a média encontrada para madeira.

Para contração, foi observado que também houve variação desprezível entre os valores no sentido axial. No sentido radial, ocorreu uma variação gradativa, chegando ao estado completamente seco, com 14\%. No sentido tangencial, o valor mínimo encontrado foi de 4,1\%. Já as variações dimensionais foram maiores na direção radial.

Pereira \& Beraldo (2008) explicaram esse fenômeno em função da ausência de raios, por isso os colmos podem apresentar maior variação nessa direção anatômica. Os valores médios em porcentagem obtidos no sentido axial se devem ao fato de as células do bambu estarem dispostas no sentido longitudinal, pois essa espécie é desprovida de raios.

Os valores encontrados para a relação $T / R$ foram menores que 1,0 , enquanto o inchamento e a contração radiais foram superiores aos tangenciais. Esse resultado é confirmado por Morita et al. (2010), que destacaram que essa espécie possui coeficiente de anisotropia próximo de 1,0, ou seja, a largura e a espessura incham ou contraem na mesma proporção, atribuindo maior estabilidade dimensional ao bambu, quando comparado com a madeira, e tornando essa espécie atrativa para movelaria. Uma vez que as maiores contrações e inchamento das lâminas, taliscas ou ripas de bambu ocorrerão no sentido da espessura, ocasionando menores empenamentos durante o processo de secagem, a maior estabilidade das lâminas será no sentido da largura, ao contrário do que ocorre com a madeira. A retratibilidade volumétrica foi de $15,41 \%$, sendo classificada como valor médio quando comparada com a madeira.

\section{CONCLUSÕES}

A composição anatômica do colmo do bambu estudado está em conformidade com os dados contidos na literatura. As fibras do bambu Dendrocalamus giganteus Munro possuem comprimento médio de 2,72 $\mathrm{mm}$, o que é responsável pela resistência da polpa de celulose fabricada com bambu. A susceptibilidade dessa espécie ao ataque de brocas está relacionada à quantidade de parênquima nos colmos (aproximadamente 50\%). 
A posição de retirada das amostras no sentido longitudinal do bambu influenciou nas massas específicas básica e anidra e na umidade. A retratibilidade demonstrou comportamento inverso às gimnospermas e às angiospermas dicotiledôneas, uma vez que os maiores valores para essa característica ocorrem no sentido radial (espessura) das amostras.

\section{AGRADECIMENTOS}

À Fundação de Amparo à Pesquisa do Estado do Espírito Santo (FAPES), pela concessão de bolsa de Mestrado ao primeiro autor do artigo.

\section{STATUS DA SUBMISSÃO}

Recebido: 11 mar., 2013

Aceito: 24 abr., 2015

\section{AUTOR(ES) PARA CORRESPONDÊNCIA}

\section{Juarez Benigno Paes}

Departamento de Ciências Florestais e da Madeira, Universidade Federal do Espirito Santo - UFES, Av. Gov. Lindemberg, 316, Centro, CEP 29550-000, Jeronimo Monteiro, ES, Brasil e-mail: jbp2@uol.com.br

\section{APOIO FINANCEIRO}

Este artigo contou com financiamento parcial da FAPES, por meio de bolsa de mestrado à autora Flávia Maria Silva Brito.

\section{REFERENCIAS}

Almeida JA No, Testezlaf R, Matsura EE. Características hidráulicas de tubos de bambu gigante (Dendrocalamus giganteus). Revista Brasileira de Engenharia Agrícola e Ambiental 2000; 4(1): 1-7. http://dx.doi.org/10.1590/ S1415-43662000000100001.

Associação Brasileira de Normas Técnicas - ABNT. NBR 7190: Projeto de estruturas de madeira. Anexo B: determinação das propriedades das madeiras para projetos de estruturas. Rio de Janeiro; 1997. 107 p.

Azzini A, Beraldo AL. Determinação de fibras celulósicas e amido em cavacos laminados de três espécies de bambu gigante. Scientia Forestalis 2000; (57): 45-51.
Beraldo AL, Azzini A. Bambu: características e aplicações. Guaíba: Agropecuária; 2004. 128 p.

Beraldo AL, Rivero LA. Bambu laminado colado. Floresta e Ambiente 2003; 10(2): 36-46.

Beraldo AL, Zoulalian A. Bambu: material alternativo para construções rurais. In: Anais do V Encontro Brasileiro em Madeiras e Estruturas de Madeira [CD-ROM]; 1995; Belo Horizonte. Belo Horizonte: EEUFMG; 1995.

Berndsen RS, Klitzke RJ, Batista DC, Nascimento EM, Ostapiv F. Propriedades físicas do bambu-mossô (Phyllostachys pubescens Mazel ex H. de Lehaie) em diferentes idades e posições do colmo. Floresta 2009; 40(1): 183-192.

Brito JO, Tomazello M Fo, Salgado ALB. Produção e caracterização do carvão vegetal de espécies e variedades de bambu. Scientia Forestalis 1987; (36): 13-17.

Ciaramello D, Azzini A. Bambu como matéria-prima para papel. V - Estudos sobre o emprego de quatro espécies de Dendrocalamus, na produção de celulose sulfato. Bragantia 1971; 30(24): 1-16.

Comisión Panamericana de Normas Técnicas - COPANT. Descripción de características generales, macroscópicas de las maderas angiospermas dicotiledóneas. COPANT 1974; 30: 1-19.

Ferreira GCS. Vigas de concreto armadas com taliscas de bambu Dendrocalamus giganteus [tese]. Campinas: Universidade Estadual de Campinas; 2007. 195 p.

Ferreira L. Periodicidade do crescimento e formação da madeira de algumas espécies arbóreas de florestas estacionais semidecíduas da região Sudeste do Estado de São Paulo [dissertação]. Piracicaba: Universidade de São Paulo; 2002. 122 p.

George J. Preservative treatment of bamboo, rubber wood and coconut palm. In: Findlay WPK. Preservation of timber in the tropics. Dordrecht: Martinus Nijhoff: Dr W. Junk Publishers; 1985. p. 233-247.

Hidalgo Lopez O. Bamboo: the gift of the Gods. Bogotá: D’vinni; 2003. 553 p.

Iawa Committiee - IAWA. List of microscopic features for hardwood identification with an appendix on nonanatomical information. IAWA Bulletin 2007; 10(3):219-332.

Liese W. The anatomy of bamboo culms. 18. ed. Beijing: INBAR; 1998. 204 p.

Lima JSS, Silva AS, Oliveira RB, Cecílio RA, Xavier AC. Variabilidade temporal da precipitação mensal em Alegre ES. Revista de Ciências Agronômicas 2008; 39(2): 327-332.

Miskalo EP. Avaliação do potencial de utilização de bambu (Dendrocalamus giganteus) na produção de painéis de partículas orientadas [dissertação]. Curitiba: Universidade Tecnológica Federal do Paraná; 2009. 130 p. 
Morita BS, Barbosa JC, Fonseca KAV, Caraschi JC, Akira MI. Estabilidade dimensional e coeficiente anisotrópico do bambu Dendrocalamus giganteus para aplicação na indústria moveleira. In: Anais do XII Encontro Brasileiro em Madeiras e em Estruturas de Madeira [CD-ROM]; 2010; Lavras. Lavras: UFLA; 2010.

Ostapiv F. Resistência mecânica do material compósito: madeira de eucalipto-lâmina de bambu [tese]. Guaratinguetá: Universidade Estadual Paulista; 2011. 155 p.

Pereira MAP, Beraldo AL. Bambu de corpo e alma. Bauru: Canal 6; 2008. 240 p.
Ramalho RS. O uso de macerado no estudo anatômico de madeiras. Viçosa: UFV; 1987. 4 p.

Salamon C. Ensaios para viabilizar a laminação do bambu Dendrocalamus giganteus em operações de torneamento sem centros [tese]. Guaratinguetá: Universidade Estadual Paulista; 2009. 115 p.

Tiburtino RF. Qualidade e eficiência do tratamento preservativo de duas espécies de bambu [dissertação]. Jerônimo Monteiro: Universidade Federal do Espírito Santo; 2012.94 p. 